\title{
Modulator Effect of Acetic Acid on the Morphology of Luminescent Mixed Lanthanide- Organic Frameworks
}

\author{
Ana Karina Pereira Leite ${ }^{a}$ Bráulio Silva Barros ${ }^{b *}$,Joanna Kulesza ${ }^{c}$, Jarley Fagner Silva do \\ Nascimento $^{a, d}$, Dulce Maria de Araújo Melo ${ }^{a}$, Angelo Anderson Silva de Oliveira ${ }^{a}$ \\ anstituto de Química, Universidade Federal do Rio Grande do Norte, 1662, 59078-970, \\ Natal, RN, Brazil \\ ${ }^{b}$ Departamento de Engenharia Mecânica, Universidade Federal de Pernambuco, 50070-901, \\ Recife, PE, Brazil \\ ${ }^{c}$ Departamento de Química Fundamental, Universidade Federal de Pernambuco, 50070-901, \\ Recife, PE, Brazil \\ ${ }^{d}$ Instituto Federal de Educação, Ciência e Tecnologia do Rio Grande do Norte, 59500-000, \\ Macau, RN, Brazil
}

Received: December 12, 2016; Revised: May 24, 2017; Accepted: October 25, 2017

\begin{abstract}
The control of the size and morphology of Metal-Organic Frameworks is a challenge that must be overcome to ensure the use of these materials in advanced applications. Mixed Lanthanide-Organic Frameworks (MLOFs) were synthesized via solvo(hydro)thermal method and then characterized by PXRD, IR, TG/DTA, SEM and PL spectroscopy. The effect of the modulator (acetic acid) on the morphological characteristics of the obtained powders was investigated. Trivalent terbium ions were successfully incorporated into La-framework conferring green luminescence to the prepared samples. It was observed that a gradual increase in acetic acid concentration led to the morphology change from micro-rods to flower-like small particle agglomerates. Moreover, a higher concentration of the acetic acid prevented the crystallization of secondary phases.
\end{abstract}

Keywords: $M O F s$, acetic acid, morphology, lanthanides, photoluminescence.

\section{Introduction}

Metal-Organic Frameworks (MOFs) have attracted much interest in recent years due to their intriguing structural and topological characteristics as well as the variety of potential applications for these materials. MOFs are composed of metallic ions or clusters interconnected by polytopic organic linkers along one-, two-, or three-dimensions ${ }^{1,2}$. Different combinations of metals and organic binders may provide an infinite number of MOF structures with distinct physical and chemical properties ${ }^{3,4}$. The unique characteristics of MOFs such as high surface area, tunable porosity and high thermal and chemical stability, allow its application in gas storage and separation, catalysis, drug delivery, imaging, and sensing.

Lanthanide-based MOFs are especially attractive for the development of light-emitting materials ${ }^{2,5,6}$. The lanthanide metals comprise a group of fifteen chemical elements from lanthanum (La) to lutetium of the atomic number 57 and 71 , respectively. They show unique properties derived from their electronic configurations, which are characterized (except $\mathrm{La}$ and $\mathrm{Lu}$ ) by the presence of partially filled $4 \mathrm{f}$ orbitals ${ }^{7}$. These peculiar characteristics combined with the fascinating structural diversity of MOFs may lead to improved or even new properties.

*e-mail: braulio.barros@ufpe.br
It is well known that one of the most important factors that drive the formation of the desired structure of MOFs are synthetic parameters. Among them, parameters such as temperature, time of reaction, solvent, $\mathrm{pH}$ and metal/ ligand molar ratio are the most affecting on the structure and morphology of prepared materials ${ }^{8-14}$. Although MOFs in their bulk form may offer the needed properties to destine them for a series of applications, nano-sized MOFs are required mostly for biomedical applications such as drug delivery or imaging probes ${ }^{5,6,15}$

Several reports on the preparation of nano-MOFs can be found in the literature. Among them: room-temperature precipitation $^{16}$, water-in-oil microemulsion-based method ${ }^{17}$, surfactant-assisted high-temperature synthesis ${ }^{18,19}$, microwaveor ultrasonic-assisted method ${ }^{18}$ are the most frequently used approaches for the preparation of MOF nanomaterials. However, the control of the size and shape of nano-MOFs particles is still a great challenge.

Recently, the coordination modulation method was applied for the fabrication of nano-sized MOFs ${ }^{20,21}$. This method is based on the addition of a monodentate ligand (called modulator or capping agent) in the reaction mixture. The modulator has only one functional group similar to the polytopic organic linker. Modulators compete with polytopic organic binders by coordination to the metal ions preventing 
the growth of MOF crystals. Therefore, this mechanism tends to favor the formation of nano-scale MOFs.

Several monodentate binders such as acetic acid ${ }^{22,23}$, benzoic acid $^{24}$, dodecanoic acid or lauric acid ${ }^{25,26}$ used as capping agents have been reported in the literature. These monocarboxylate ligands were used to modulate the morphology and crystal size of $\mathrm{MOFs}^{22,26}$.

In this paper, we present the synthesis and characterization of $\mathrm{Tb}^{3+}$-doped La-MOFs prepared by a hydro(solvo)thermal method using the acetic acid as a modulator. The effects of both, the reactant content and the modulator concentration on the morphological properties of these materials, were investigated.

\section{Experimental section}

\subsection{Materials and methods}

Reactants and solvents were used as received without further purification. Lanthanum nitrate hexahydrate $\left(\mathrm{La}\left(\mathrm{NO}_{3}\right)_{3} \cdot 6 \mathrm{H}_{2} \mathrm{O}\right)$, acetic acid $\left(\mathrm{CH}_{3} \mathrm{COOH}\right)$, nitric acid $\left(\mathrm{HNO}_{3}\right)$, $\mathrm{N}, \mathrm{N}$-dimethylformamide (DMF) and ethanol (EtOH) were acquired from Vetec. Hydrogen peroxide $\left(\mathrm{H}_{2} \mathrm{O}_{2}\right)$ was purchased from Dinâmica. Terbium oxide $\left(\mathrm{Tb}_{4} \mathrm{O}_{7}\right)$ and isophthalic acid $\left(1,3-\mathrm{H}_{2} \mathrm{BDC}\right)$ were acquired from Sigma-Aldrich.

\subsection{Synthesis of $\mathrm{Tb}^{3+}$ - doped La-MOFs}

In a typical procedure, terbium nitrate was prepared by dissolving a stoichiometric amount of $\mathrm{Tb}_{4} \mathrm{O}_{7}$ in an aqueous solution of $\mathrm{HNO}_{3}$, and simultaneously adding a small amount of $\mathrm{H}_{2} \mathrm{O}_{2}$ to reduce $\mathrm{Tb}^{4+}$ to $\mathrm{Tb}^{3+}$. This solution was kept under stirring at $80^{\circ} \mathrm{C}$ until complete solvent evaporation. Next, the stoichiometric amounts of $\mathrm{La}\left(\mathrm{NO}_{3}\right)_{3} \cdot 6 \mathrm{H}_{2} \mathrm{O}$ and $1,3-\mathrm{H}_{2} \mathrm{BDC}$ were added, and then dissolved at room temperature in $7 \mathrm{~mL}$ of DMF and $3 \mathrm{~mL}$ of distilled water. The resulting solution was transferred to a sealed glass vial which was maintained at $90{ }^{\circ} \mathrm{C}$ for four days. Finally, the obtained white solid was filtered, washed with DMF and ethanol, dried overnight at $60{ }^{\circ} \mathrm{C}$ and then characterized.

To evaluate the effect of total reactant concentration, three samples were synthesized using the following amounts (in mmol) of $\mathrm{Tb}^{3+}: \mathrm{La}^{3+}: 1,3-\mathrm{H}_{2} \mathrm{BDC},(0.02: 0.9: 1),(0.01: 0.49: 0.5)$ and (0.002:0.098:0.1). These samples were designated as MLOF1, MLOF2 and MLOF3a, respectively.

Three other samples, so called, MLOF3b, MLOF3c, and MLOF3d, were synthesized as MLOF3a. However, instead of $3 \mathrm{ml}$ of distilled water, the mixture of acetic acid and distilled water in the following ratio in $\mathrm{mL}:(0.5: 2.5),(1.5: 1.5)$ and (2.0:1.0), respectively, were used. In this case, the goal was to evaluate the effects of the modulator concentration on the morphological characteristics of the products.

\subsection{Sample characterizations}

Powder X-ray diffraction (PXRD) data were recorded on a Bruker D2 Phaser diffractometer using $\mathrm{Cu} \mathrm{K} \alpha$ radiation $(\lambda=1.5406 \AA)$ with a Ni filter, operating at $30 \mathrm{kV}$ and 10 $\mathrm{mA}$. The PXRD patterns were recorded between 5 and $70^{\circ}$ at steps of $0.02^{\circ}$.

Attenuated total reflection Fourier transform infrared (ATR-FTIR) experiments were carried out on a Bruker Vertex $70 / \mathrm{v}$ spectrometer in the range of $400-4000 \mathrm{~cm}^{-1}$.

TG/DTA curves were obtained in the temperature range of $25-800^{\circ} \mathrm{C}\left(10^{\circ} \mathrm{C} / \mathrm{min}\right)$ using a thermogravimetric and simultaneous calorimeter analyzer model SDTQ600 manufactured by TA Instruments under atmospheric air at a flow rate of $50 \mathrm{~mL} / \mathrm{min}$.

Morphological analysis of powders was performed on Scanning Electron Microscopy (SEM) in a Shimadzu Microscope equipment with $15 \mathrm{kV}$ acceleration, Superscan SSX-550 TM. The excitation and emission spectra were collected in a solid state at $298 \mathrm{~K}$ on a K2 spectrofluorometer (ISS) equipped with $300 \mathrm{~W}$ Xe lamp.

\section{Results and discussion}

\subsection{Sample characterization}

\subsubsection{Powder XRD and Structure}

Lanthanide nitrates and isophthalic acid were used as starting materials in the synthesis of Mixed LanthanideOrganic Frameworks (MLOFs). The produced powders were characterized by XRD to determine the crystalline phases, and the patterns are shown in Figure 1. Surprisingly, no phase containing the deprotonated form of isophthalic acid was identified. Instead of that, it was found that the most intense diffraction lines match well with the simulated pattern from the single-crystal structure of $\left[\mathrm{Ce}(\mathrm{HCOO})_{3}\right]_{\mathrm{n}}$, indicating that they are isostructural. Low-intensity peaks in the range of $2 \theta 7.5-10^{\circ}$ suggest the presence of a Lanthanide $(\mathrm{Ln})$ Complex $\left[\operatorname{Ln}_{6}\left(\mu_{3}-\mathrm{O}\right)_{4}\left(\mu_{3}-\mathrm{OH}\right)_{4}(\mathrm{HCOO})_{10}\left(\mathrm{NO}_{3}\right)_{4}\right] \cdot(\mathrm{NO}$ $\left.\left.\left.{ }_{3}\right)_{3}\left(\mathrm{NH}_{4}\right)_{5}\left(\mathrm{H}_{2} \mathrm{O}\right)_{5}\right)\right]$.

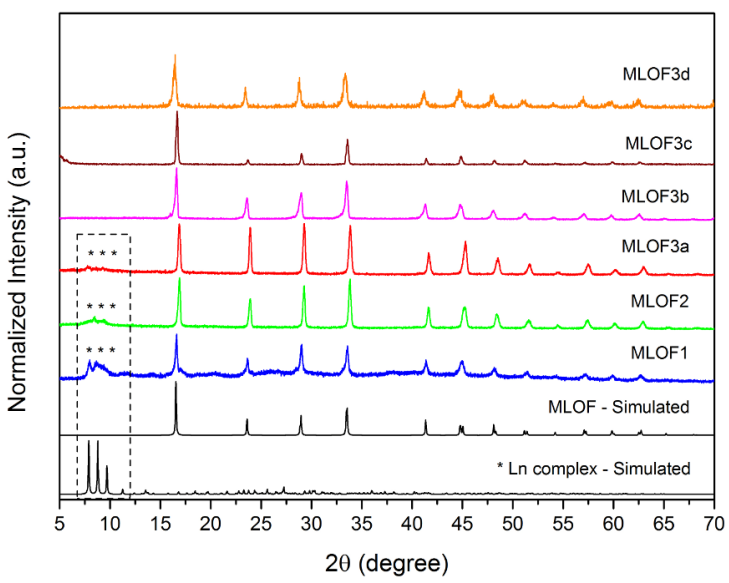

Figure 1. PXRD patterns of the synthesized MLOFs samples in comparison with the simulated from single-crystal data PXRD patterns of MLOF and Ln-Complex. 
Both structures have been previously reported by Hennig and co-workers ${ }^{27}$. Data are available in CIF COD files $\mathrm{n}^{\circ}$ 4336405 and 4336406, for Ln Complex and [Ce(HCOO) $]$ n, respectively. The peaks related to the Ln Complex are observed in the diffraction patterns of the samples MLOF1, MLOF2, and MLOF3a. Worth noting is the fact that the intensity of these peaks increases for samples prepared with a higher total concentration of reactants. Samples MLOF3b, MLOF3c, and MLOF3d, were synthesized using the same starting reactants, but with the addition of acetic acid (modulator). In this case, only the main phase was formed, which indicates that the modulator may also inhibit the crystallization of the Ln Complex.

The main phase identified $\left[\mathrm{Ln}(\mathrm{HCOO})_{3}\right]_{\mathrm{n}}$, crystallizes in the trigonal system, space group R3m. Lanthanide (Ln $=\mathrm{La}, \mathrm{Tb}$ ) ions are nine-coordinated to oxygen atoms from formate ions. As depicted in Figure 2a, one oxygen atom from the formate ion is shared by two lanthanide ions, whereas the second oxygen atom of the same carboxylate group is coordinated to a third single lanthanide ion. The crystalline framework is presented in Figure 2b. Chains of Ln atoms lie along the c-axis and are interconnected through formate ions, forming triangular channels.

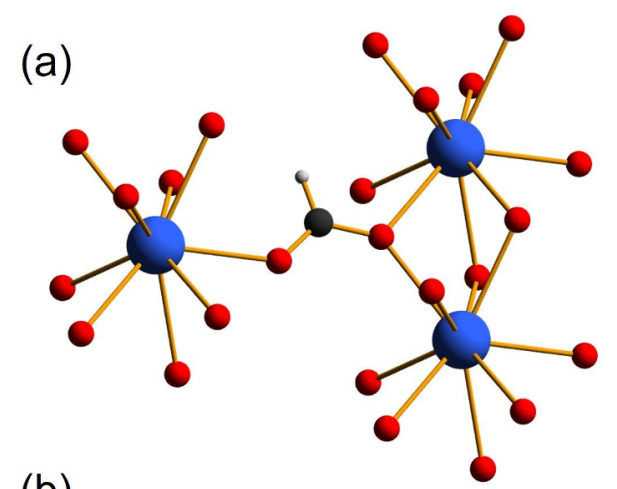

(b)

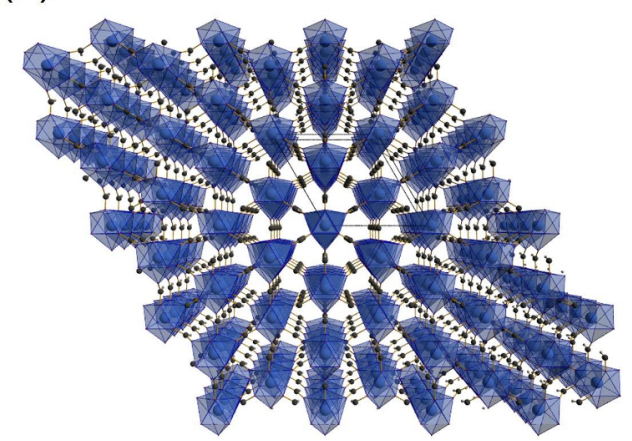

Figure 2. View of the obtained La/Tb-MOF structure: (a) coordination environment of $\mathrm{Ln}^{3+}$ (b) and partially expanded framework. Color code: black (carbon), red (oxygen), gray (hydrogen) and blue (lanthanum or terbium).
Since the formic acid was not used as the starting reactant, the presence of the formate ion in the crystalline structure of the MLOF can be explained by the process of DMF hydrolysis. When hydrolyzed, DMF decomposes forming dimethylamine and formate ions according to the reaction presented below ${ }^{28-31}$.

$$
\begin{aligned}
& \left(\mathrm{CH}_{3}\right)_{2} \mathrm{~N}-\mathrm{CHO}+\mathrm{H}_{2} \mathrm{O} \rightarrow \mathrm{HCOOH}+ \\
& \left(\mathrm{CH}_{3}\right) \mathrm{HN} \rightarrow \mathrm{HCOO}^{-}+\mathrm{H}_{2} \mathrm{~N}\left(\mathrm{CH}_{3}\right)_{2}^{+}
\end{aligned}
$$

\subsubsection{IR spectra}

In the IR spectra of the prepared samples, no bands at around $1670 \mathrm{~cm}^{-1}$ can be observed (Figure 3 ) what indicates the absence of the protonated carboxylic acid $\mathrm{COOH}$ groups in the structure. Samples MLOF3a-MLOF3d have almost identical IR spectra confirming the formation of the same pure-phase of Ln-formate (as identified by XRD). The bands at around 1573 and in the region of $1428-1362 \mathrm{~cm}^{-1}$ can be observed and correspond to the stretching, asymmetric $\left(v_{\text {as }}\right)$ and symmetric $\left(v_{\mathrm{s}}\right)$ vibrations of $\mathrm{COO}^{-}$groups, respectively. Although the spectra of MLOF1 and MLOF2 also contain these bands, a greater number of the bands assigned to $\mathrm{COO}^{-}$vibrations may suggest the presence of the second absorbing species with COO-Ln bonds. This is consistent with the XRD results of the samples MLOF1, MLOF2 and MLOF3a, which suggest the presence of a Ln Complex as a secondary phase. The presence of the Ln Complex in MLOF3a is not evident based on the IR spectrum, probably due to its small quantity in the sample. Nevertheless, XRD pattern of MLOF3a presents peaks corresponding to both phases.

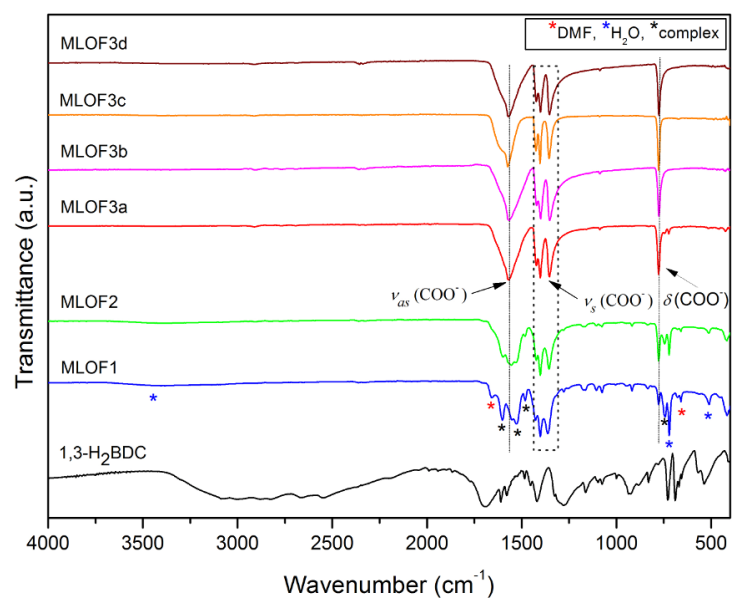

Figure 3. FTIR spectra of the prepared MLOF samples compared to the pure $1,3-\mathrm{H}_{2} \mathrm{BDC}$.

Both samples MLOF1 and MLOF2 presumably contain solvent molecules in the structure. The bands around 1656 and $662 \mathrm{~cm}^{-1}$ may be attributed, respectively, to the stretching 
$v(\mathrm{C}=\mathrm{O})$ and $\delta(\mathrm{OCN})$ bending vibrations of non-coordinated DMF molecule. The broadband at around $3400 \mathrm{~cm}^{-1}$ and the bands at 720 and $511 \mathrm{~cm}^{-1}$ suggest the presence of a coordinated water in both samples. The bands attributed to the solvent bond vibrations are more intense for MLOF1 than for MLOF2 accounting for the higher number of solvent molecules adsorbed/coordinated in the structure. Water molecules may originate from the hexanuclear complex present in the structure of both samples. Also, XRD data showed the greater quantity of the complex phase for MLOF1 than for MLOF2, what may explain the difference in the intensity of solvent bands.

\subsubsection{Thermal analysis}

TG-DTA curves of the synthesized powders are shown in Figure 4. All samples show a continuous mass loss event from room temperature until $300{ }^{\circ} \mathrm{C}$ associated with the presence of solvent molecules in the pores and on the particle surface. This weight loss remains smaller than 5\%, except for the sample MLOF3d, reaching around 10\%.

The decomposition of $\left[\mathrm{Ln}(\mathrm{HCOO})_{3}\right]_{\mathrm{n}}(\mathrm{Ln}=\mathrm{La}$ and $\mathrm{Tb})$ takes place in two steps. The first weight loss at 350-400 ${ }^{\circ} \mathrm{C}$, an endothermic event, corresponds to the formation of lanthanide carbonates. The second event around $650-700{ }^{\circ} \mathrm{C}$, also endothermic, is associated with the decomposition of carbonate and its transformation into corresponding oxides.
The weight loss at $550-600{ }^{\circ} \mathrm{C}$ is observed only for samples MLOF1 and MLOF2. This endothermic event is associated with the decomposition of the secondary phase, Ln Complex.

\subsubsection{Scanning Electron Microscopy (SEM)}

The effect of the total reactant and the modulator (acetic acid) concentration on the microstructure of the powders were evaluated by scanning electron microscopy. The micrographs are displayed in Figure 5. Two microstructures micro-rods with a length greater than $10 \mu \mathrm{m}$ and agglomerates of the smaller size particles with no well-defined shape, can be distinguished in Figure 5a. The first microstructure is associated with the crystal structure $\left[\mathrm{Ln}(\mathrm{HCOO})_{3}\right]_{\mathrm{n}}(\mathrm{Ln}=\mathrm{La}$ and $\mathrm{Tb})$, whereas the second one corresponds to the secondary phase, both previously identified by XRD.

It can be noticed that the quantity of the secondary phase decreases for a lower total reactants concentration (Figure 5c).

Samples MLOF3d (micrograph 5d), MLOF3c (micrograph 5e) and MLOF3b (micrograph 5f), were prepared with addition of $0.5,1.5$ and $2.0 \mathrm{~mL}$ of acetic acid (modulator), respectively. As can be seen, micrographs $5 \mathrm{e}$ and $5 \mathrm{f}$ presents very similar microstructure composed of micro-rods with a length up to $30 \mu \mathrm{m}$. On the other hand, the micrograph $5 \mathrm{~d}$ does not show micro-rods, but agglomerates of small particles with flower-like morphology. It appears that at higher concentrations, acetic acid modulates both, the shape
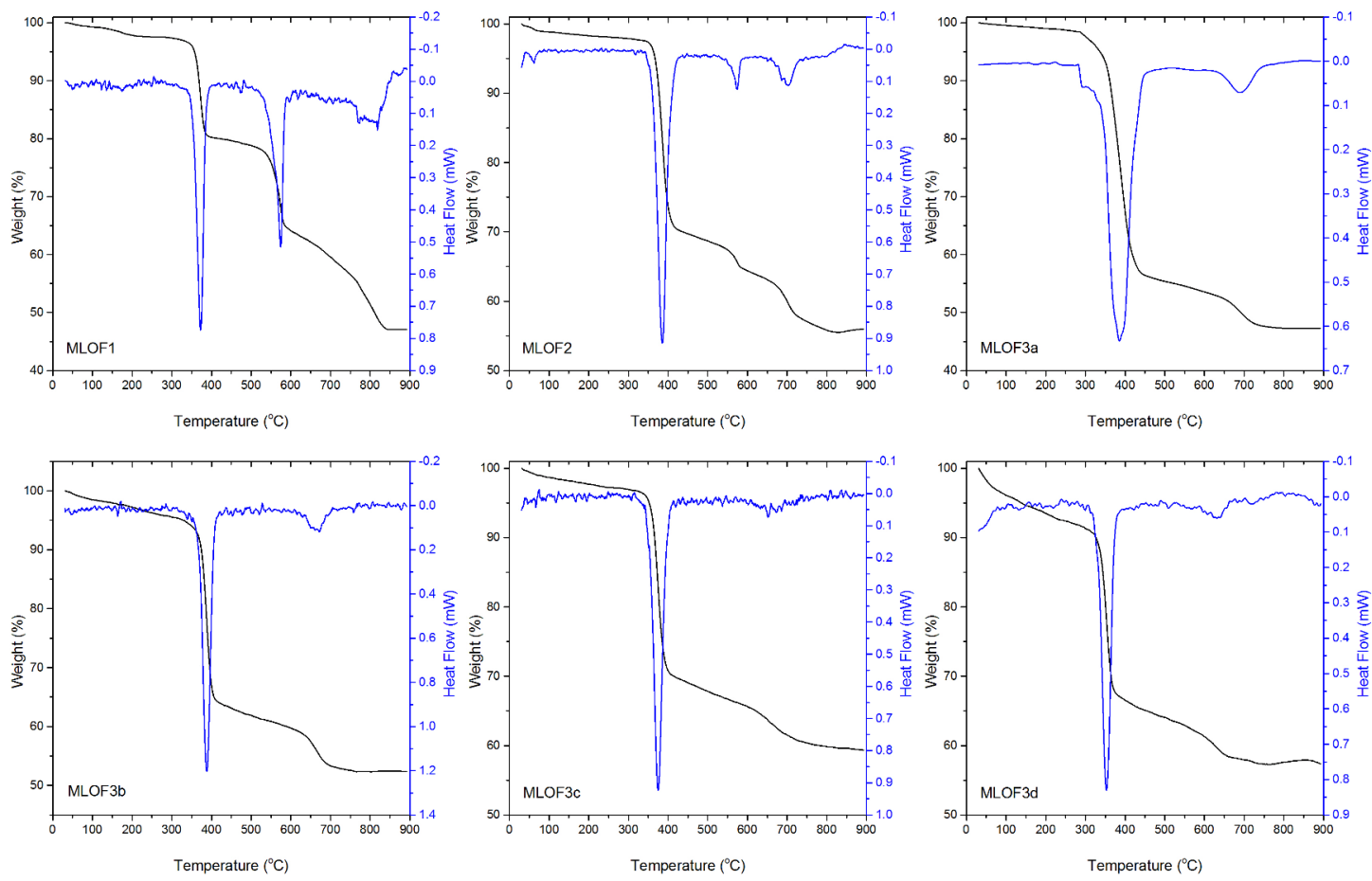

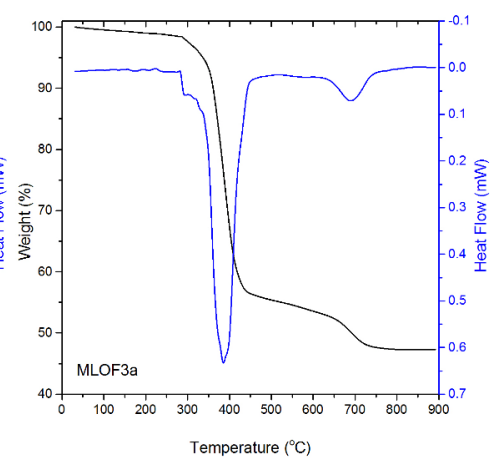

Temperature $\left({ }^{\circ} \mathrm{C}\right)$

Figure 4. TG/DTA profiles of MLOF samples. 

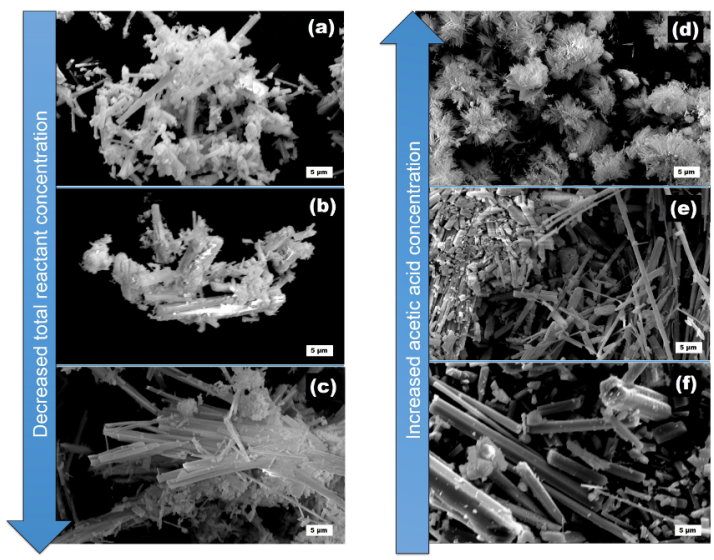

Figure 5. SEM images of MLOF samples; MLOF1 (a), MLOF2 (b), MLOF3a (c), MLOF3d (d), MLOF3c (e), MLOF3b (f).

and the size of particles. Moreover, the presence of acetic acid prevents the formation of the secondary phase or at least its presence is less evident (see Figures $5 \mathrm{~d}-5 \mathrm{f}$ ). These results are consistent with the PXRD diffractograms which showed only peaks corresponding to the pure-phase MLOF in the case of MLOF3b, MLOF3c, and MLOF3d samples. Similar conclusions were made on the basis of IR spectra.

\subsection{Photophysical properties}

The solid-state excitation and emission spectra of the produced powders were measured at room temperature (see Figure 6). A broadband with two humps is observed in the excitation spectra (dashed lines) obtained by monitoring the emission of the ${ }^{5} \mathrm{D}_{4} \rightarrow{ }^{7} \mathrm{~F}_{5}$ transition of $\mathrm{Tb}^{3+}$ ions at $544 \mathrm{~nm}$. The first hump, with a maximum at $251 \mathrm{~nm}$, can be assigned to the charge-transfer band between oxygen and terbium ions, while de second one at $295 \mathrm{~nm}$ may be attributed to the $4 f^{8} \rightarrow 4 f^{7} 5 d^{1}\left(T^{3+}\right)$ transition ${ }^{32,33}$. It is worth noting that these two bands present different intensity ratio for samples prepared in the presence (MLOF3b, MLOF3c, and MLOF3d) or absence of the modulator (MLOF1, MLOF2 and MLOF3a). The smaller intensity ratio $\left(\mathrm{I}_{251} / \mathrm{I}_{295}\right)$ in the second case, may suggest an overlapping of the bands corresponding to both, MLOF and the secondary phase. A third low-intensity band is observed in the spectrum of the sample MLOF3c, apparently related to the $\mathrm{Tb}^{3+}$ ions.

All samples displayed the characteristic green photoluminescence of $\mathrm{Tb}^{3+}$ when exposed to UV light from a standard lamp (254 $\mathrm{nm}$ ). The emission spectra (solid line) were recorded upon excitation at $295 \mathrm{~nm}$. Four narrow and intense peaks present at 486,544, 584 and $620 \mathrm{~nm}$ are attributed to the ${ }^{5} \mathrm{D}_{4}{ }^{-7} \mathrm{~F}_{6},{ }^{5} \mathrm{D}_{4}-{ }^{7} \mathrm{~F}_{5},{ }^{5} \mathrm{D}_{4}{ }^{-7} \mathrm{~F}_{4}$ and ${ }^{5} \mathrm{D}_{4}{ }^{7} \mathrm{~F}_{3}$ transitions of $\mathrm{Tb}^{3+}$, respectively.

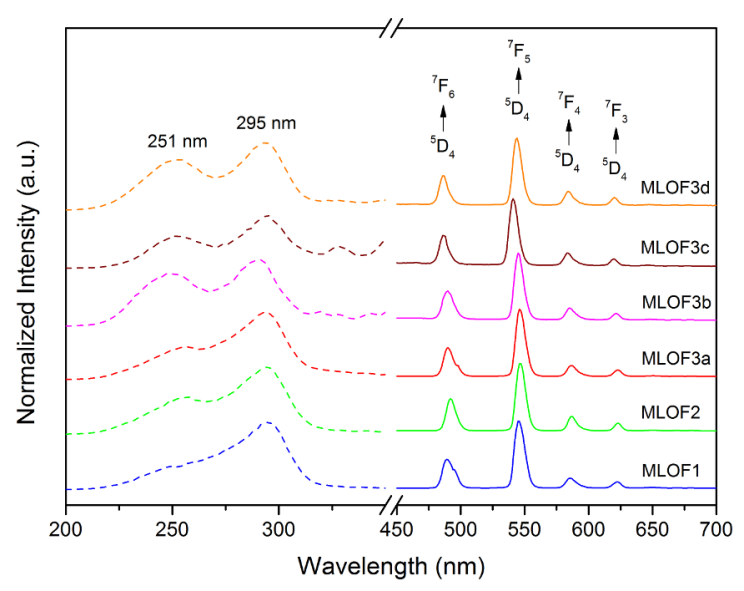

Figure 6. Solid-state excitation (dashed line, $\lambda_{\text {em }}=544 \mathrm{~nm}$ ) and emission (solid line, $\lambda_{\mathrm{ex}}=295 \mathrm{~nm}$ ) spectra of prepared MLOF samples measured at room temperature.

\section{Conclusions}

The solvo(hydro)thermal reaction between generated in situ terbium nitrate, isophthalic acid and lanthanum nitrate in $\mathrm{DMF} / \mathrm{H}_{2} \mathrm{O}$ solvent mixture carried out at $90^{\circ} \mathrm{C}$ for four days, yielded Mixed-Lanthanide Frameworks. Surprisingly, instead of isophthalate linker, the formate anions were coordinated to the Ln centers. The increase in a total reactants concentration furnished the higher quantity of a secondary minor phase identified as Ln Complex. It was demonstrated that the presence of this impurity could be eliminated by the addition of the acetic acid used as a capping agent. The higher concentration of the acetic acid also influenced on the size and shape of MOF particles. The prepared samples exhibited green luminescent upon excitation at $295 \mathrm{~nm}$. Further studies will be performed to investigate the modulator effect of the acetic acid on luminescent properties of these materials.

\section{Acknowledgments}

The authors thank Federal University of Pernambuco, School of Science and Technology/UFRN and Federal Institute of Education, Science and Technology of the Rio Grande do Norte (IFRN). This work was supported by CNPq (grant no. 407445/2013-7) and PRONEX/FACEPE/CNPq (grant no. APQ-0675-1.06/14).

\section{References}

1. Zhou H, Longo JR, Yaghi OM. Introduction to Metal-Organic Frameworks. Chemical Reviews. 2012;112(2):673-674.

2. James SL. Metal-organic frameworks. Chemical Society Reviews. 2003;32(5):276-288 
3. Quirós J, Boltes K, Aguado S, Guzman de Villoria R, Vilatela JJ, Rosal R. Antimicrobial metal-organic frameworks incorporated into electrospun fibers. Chemical Engineering Journal. 2015;262:189-197.

4. Liu D, Lu K, Poon C, Lin W. Metal-Organic Frameworks as Sensory Materials and Imaging Agents. Inorganic Chemistry. 2014;53(4):1916-1924.

5. Della Rocca J, Liu D, Lin W. Nanoscale Metal-Organic Frameworks for Biomedical Imaging and Drug Delivery. Accounts of Chemical Research. 2011;44(10):957-968.

6. Kuppler RJ, Timmons DJ, Fang QR, Li JR, Makal TA, Young $\mathrm{MD}$, et al. Potential applications of metal-organic frameworks. Coordination Chemistry Reviews. 2009;253(23-24):3042-3066.

7. Barros BS, de Lima AC, da Silva ZR, Melo DMA, Alves S Jr. Synthesis and photoluminescent behavior of $\mathrm{Eu}^{3+}$-doped alkaline-earth tungstates. Journal of Physics and Chemistry of Solids. 2012;73(5):635-640.

8. Stock N, Biswas S. Synthesis of Metal-Organic Frameworks (MOFs): Routes to Various MOF Topologies, Morphologies and Composites. Chemical Reviews. 2012;112(2):933-969.

9. Kulesza J, Barros BS, Alves Júnior S, Oliveira CAF, Melo DMA, Chojnacki J. Benzene-induced hydro(solvo)thermal synthesis of $\mathrm{Cu}^{2+}$ and $\mathrm{Zn}^{2+}$ coordination polymers based on 1,3-benzenedicarboxylate. Materials Chemistry and Physics. 2014;143(3):1522-1527.

10. Zhong SL, Rong X, Zhang LF, Qu WG, Gao GQ, Wu XL, et al. Terbium-based infinite coordination polymer hollow microspheres: preparation and white-light emission. Journal of Materials Chemistry. 2011;21(14):16574-16580.

11. Rossin A, Giambastiani G, Peruzzini M, Sessoli R. Amine-Templated Polymeric Lanthanide Formates: Synthesis, Characterization, and Applications in Luminescence and Magnetism. Inorganic Chemistry. 2012;51(12):6962-6968.

12. Jin LN, Liu Q, Sun WY. An introduction to synthesis and application of nanoscale metal-carboxylate coordination polymers. CrystEngComm. 2014;16(19):3816-3818.

13. Liu Q, Jin LN, Sun WY. Facile fabrication and adsorption property of a nano/microporous coordination polymer controllable size and morphology. Chemical Communications. 2012;48(70):88148816 .

14. Jahan M, Bao Q, Yang JX, Loh KP. Structure-Directing Role of Graphene in the Synthesis of Metal-Organic Frameworks Nanowire. Journal of the American Chemical Society. 2010;132(41):14487-14495.

15. Carné A, Carbonell C, Imaz I, Maspoch D. Nanoscale metalorganic materials. Chemical Society Reviews. 2011;40(1):291305.

16. Sun X, Dong S, Wang E. Coordination-Induced Formation of Submicrometer-Scale, Monodisperse, Spherical Colloids of Organic-Inorganic Hybrid Materials at Room Temperature. Journal of the American Chemical Society. 2005;127(38):1310213103.

17. Rieter WJ, Taylor KML, An H, Lin W, Lin W. Nanoscale Metal-Organic Frameworks as Potential Multimodal Contrast
Enhancing Agents. Journal of the American Chemical Society. 2006;128(28):9024-9025.

18. Hatakeyama W, Sanchez TA, Rowe MD, Serkova NJ, Liberatore MW, Boyes SG. Synthesis of Gadolinium Nanoscale MetalOrganic Framework with Hydrotropes: Manipulation of Particle Size and Magnetic Resonance Imaging Capability. ACS Applied Materials \& Interfaces. 2011;3(5):1502-1510.

19. Taylor KM, Jin A, Lin W. Surfactant-Assisted Synthesis of Nanoscale Gadolinium Metal-Organic Frameworks for Potential Multimodal Imaging. Angewandte Chemie - International Edition. 2008;47(40):7722-7725.

20. McGuire CV, Forgan RS. The surface chemistry of metal-organic frameworks. Chemical Communications. 2015;51:5199-5217.

21. Cho W, Lee HJ, Oh M. Growth-Controlled Formation of Porous Coordination Polymer Particles. Journal of the American Chemical Society. 2008;130(50):16943-16946.

22. Tsuruoka T, Furukawa S, Takashima Y, Yoshida K, Isoda S, Kitagawa S. Nanoporous Nanorods Fabricated by Coordination Modulation and Oriented Attachment Growth. Angewandte Chemie - International Edition. 2009;48(26):4739-4743.

23. Chin JM, Chen EY, Menon AG, Tan HY, Hor ATS, Schreyer MK, et al. Tuning the aspect ratio of NH2-MIL-53(Al) microneedles and nanorods via coordination modulation. CrystEngComm. 2013;15(4):654-657.

24. Schaate A, Roy P, Godt A, Lippke J, Waltz F, Wiebcke M, et al. Modulated Synthesis of Zr-Based Metal-Organic Frameworks: From Nano to Single Crystals. Chemistry A European Journal. 2011;17(24):6643-6651.

25. Diring S, Furukawa S, Takashima Y, Tsuruoka T, Kitagawa S. Controlled Multiscale Synthesis of Porous Coordination Polymer in Nano/Micro Regimes. Chemistry of Materials. 2010;22(16):4531-4538.

26. Umemura A, Diring S, Furukawa S, Uehara H, Tsuruoka T, Kitagawa S. Morphology Design of Porous Coordination Polymer Crystals by Coordination Modulation. Journal of the American Chemical Society. 2011;133(39):15506-15513.

27. Hennig C, Ikeda-Ohno A, Kraus W, Weiss S, Pattison P, Emerich $\mathrm{H}$, et al. Crystal Structure and Solution Species of Ce(III) and $\mathrm{Ce}(\mathrm{IV})$ Formates: From Mononuclear to Hexanuclear Complexes. Inorganic Chemistry. 2013;52(20):11734-11743.

28. Kandori K, Ohkoshi N, Yasukawa A, Ishikawa T. Morphology control and texture of hematite particles by dimethylformamide in forced hydrolysis reaction. Journal of Materials Research. 1998;13(6):1698-1706.

29. Huang G, Yang P, Wang N, Wu JZ, Yu Y. First lanthanide coordination polymers with $N, N$-dimethylformamide hydrolysis induced formate ligands. Inorganica Chimica Acta. 2012;384:333339.

30. Burrows AD, Cassar K, Friend RMW, Mahon MF, Rigby SP, Warren JE. Solvent hydrolysis and templating effects in the synthesis of metal-organic frameworks. CrystEngComm. 2005;7(89):548-550.

31. Samasekere P, Wang X, Kaveevivitchai W, Jacobson AJ. Reactions of Rare Earth Hydrated Nitrates and Oxides with 
Formamide: Relevant to Recycling Rare Earth Metals. Crystal Growth and Design. 2015;15(3):1119-1128.

32. Alexander D, Thomas K, Sisira S, Vimal G, Kamal PM, Biju PR, et al. Photoluminescence Properties of fully concentrated Terbium oxalate: a novel efficient green emitting phosphor. Materials Letters. 2017;189:160-163.
33. Singh LP, Singh NP, Srivastava SK. Terbium Doped $\mathrm{SnO}_{2}$ Nanoparticles as White Emitters and $\mathrm{SnO}_{2}: 5 \mathrm{~Tb} / \mathrm{Fe}_{3} \mathrm{O}_{4}$ Magnetic Luminescent Nanohybrids for Hyperthermia Application and Biocompatibility with HeLa Cancer Cells. Dalton Transactions. 2015;44(14):6457-6465. 